\title{
A Survey of Parents of Children Attending the Online Classes During the Ongoing COVID-19 Pandemic
}

\author{
Sandeep Grover ${ }^{1} \cdot$ Sandeep Kumar Goyal ${ }^{2} \cdot$ Aseem Mehra $^{1}$ • Swapnajeet Sahoo ${ }^{1} \cdot$ Samta Goyal $^{3}$
}

Received: 28 August 2020 / Accepted: 5 October 2020 / Published online: 10 October 2020

(C) Dr. K C Chaudhuri Foundation 2020

To the Editor: COVID-19 pandemic resulted in an unprecedented closure of school across the World and it caused a halt to the education system. To overcome this problem, governments have allowed continuation of education through the "online classes" or "e-learning" [1]. In India, the online classes started in some parts of India from first week of April and gradually the trend spread across the country [2]. This transition to online learning has impacted not only students who have had to adjust to a new learning environment, but also their parents who have had to deal with this emerging technology and monitoring of children round the clock [3]. To understand this, we carried out an online cross-sectional survey, in English language, after approval, by the Institute ethics committee during the period of 21 st June 2020 to 17 th July 2020 among the guardians of children attending the online classes, to assess the impact of online classes on the children and parents/guardians.

Two hundred eighty nine guardians with a mean age of 38.2 y (5.7) participated in the survey. A majority of the participants were females $(67.8 \%)$, from urban background (75.4\%) and were graduate or postgraduate $(67.5 \%)$. A majority $(93.8 \%)$ of the children were studying in private schools, (English medium); attending online live classes $(83.7 \%)$. About three-fourth of the participants (parents/ guardians) reported that online classes were less comfortable $(81.7 \%)$, and less satisfactory $(78.5 \%)$; the guardians reported

Sandeep Grover

drsandeepg2002@yahoo.com

1 Department of Psychiatry, Post Graduate Institute of Medical Education and Research, Chandigarh 160012, India

2 Department of Psychiatry, SPS Hospitals, Ludhiana, Punjab, India

3 Department of Critical Care, SPS Hospitals, Ludhiana, Punjab, India that the children had poor attention and concentration $(80.6 \%)$, had lower learning of theoretical and practical aspects of the subject (82.4\%), and were associated with lower ability of the child to sit satisfactorily for the duration of the class $(78.6 \%)$. The most common reported distraction while attending the online classes was surfing internet $(52.2 \%)$ or participation in online competitions (52.2\%). About half of the guardians reported that there was increase in irritability (45.0\%), increased demand to go to school (45.0\%), and reduction in the self-hygiene/care (43.3\%) among the children. Online classes have a negative impact on the behavior and physical health of the children. These preliminary findings suggest that the level of learning with regular classes, cannot be matched by the online classes.

\section{Compliance with Ethical Standards}

Conflict of Interest None.

\section{References}

1. Basilaia G, Kvavadze D. Transition to online education in schools during a SARS-CoV-2 Coronavirus (COVID-19) pandemic in Georgia. Pedagog Res. 2020;5:em0060.

2. Goswami K. Online classes: from meeting friends to internet problems, first-hand experiences of e-learning during Covid-19 [internet]. India Today 2020; Available at: https://www.indiatoday.in/ education-today/featurephilia/story/online-classes-virtual-classes-elearning-modi-govertnemnt-education-news-kaja-1664676-202004-08. Accessed 23 Aug 2020.

3. Canvas. New survey shows parents' top challenges with online learning [Internet]. 2020. Available at: https://www.prnewswire. com/news-releases/new-survey-shows-parents-top-challenges-withonline-learning-301049124.html. Accessed 23 Aug 2020.

Publisher's Note Springer Nature remains neutral with regard to jurisdictional claims in published maps and institutional affiliations. 